\title{
Chapter 14 \\ SkillsFuture: The Roles of Public \\ and Private Sectors in Developing \\ a Learning Society in Singapore
}

\author{
Michael Fung, Renzo Taal, and William Sim
}

\section{Abbreviations}

COVID-19 coronavirus disease

OECD Organisation for Economic Co-operation and Development

\subsection{Introduction}

In a globalized knowledge-driven economy, the biggest asset for a country according to the Organisation for Economic Co-operation and Development (OECD) is its human and intellectual capital, represented by the education and skills attainment of its populace (OECD 2019). Engendering a culture of learning with investments in high-quality education and skills development programs is the key to economic success in today's knowledge-driven digital economy.

From the turn of the millennium, a confluence of factors has generated disruptions that pose challenges to traditional education and training systems, which are becoming inadequate and inefficient in imparting the necessary skills in an environment where change is a constant. Graduates need to be adequately prepared

\footnotetext{
M. Fung ( $\varangle)$

SkillsFuture Singapore Agency, Singapore, Singapore

e-mail: Michael_FUNG@ssg.gov.sg

R. Taal

UiPath, New York, NY, USA

e-mail: renzo.taal@uipath.com

W. Sim

Trailhead Academy (Asia Pacific), Salesforce, San Francisco, CA, USA

e-mail:wsim@salesforce.com
} 
with the relevant skills, knowledge, and expertise to meet the requirements of today's and future jobs, where disruptions are changing the nature of jobs at a breakneck speed (Krishnan 2020). Skills and knowledge of the workforce are becoming obsolete within a few short years as companies transform their business models (Bughin et al. 2018). A new paradigm for education systems and pedagogy is required to provide accessible opportunities to learn new skills throughout life, enabling individuals to remain relevant and employable at the workplace.

Continuous upskilling is key to success for both organizations as well as employees in a technology-driven world. Singapore is a case in point for what a country can achieve through focused and sustained investment in human capital development.

\subsection{Disruptions to the Future of Work and Learning}

Economies and societies globally are being disrupted by a number of factors, including technological advancements fuelling the fourth industrial revolution or Industry 4.0, shifting demographics of the labor force, extended life expectancy and careers, and more recently, the economic and social impact brought about by the coronavirus disease (COVID-19) pandemic (Fig. 14.1). All these factors have profound implications on the future of work and learning.

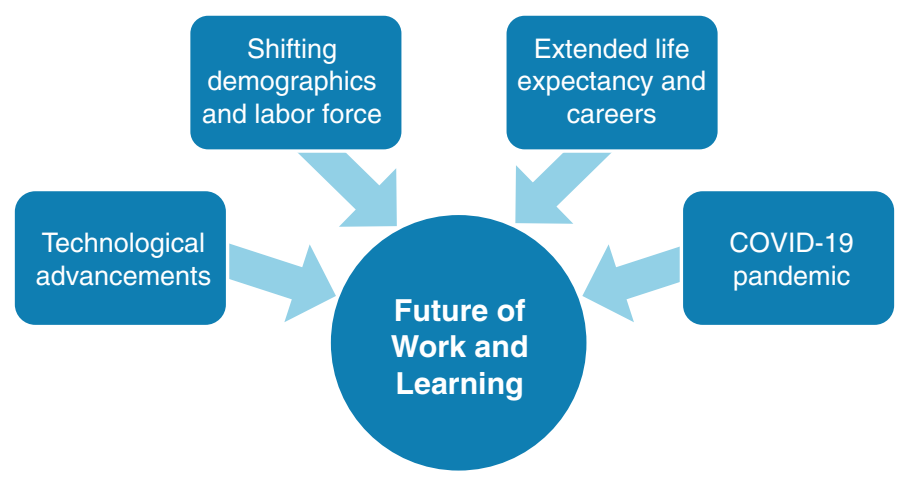

Fig. 14.1 Major drivers impacting the future of work and learning. (Disruptions have accentuated the need to speed up the development of learning societies, where access to lifelong learning for all supports the acquisition of relevant skills that will help navigate an uncertain future). COVID-19 $=$ coronavirus disease. Source Authors' representation 


\subsubsection{Technological Advancements}

Rapid advances in technologies such as artificial intelligence, robotics and automation, cloud computing, and others, along with increasing connectivity due to the internet and social media channels, have ushered in an era where today's technologies quickly become obsolete. Technological innovations are being used by companies to attract new customers, strengthen relationships with suppliers and customers, and improve productivity. Companies are seeing market share increases as they digitalize and transform.

Competitive differentiation is no longer restricted to product features, and embracing new technologies can create new and better ways of serving customers, in which a deep understanding of customers' experience in buying, using, and consuming products and services is becoming a vital component of competitive advantage (Kramer 2019). Businesses will need new capabilities to leverage on technology to develop such customer insights and raise their competitiveness. To keep up with this rapidly changing technology and innovation landscape, employees need to continually undergo training and upgrade their skill sets to match evolving industry needs.

\subsubsection{Shifting Demographics and Labor Force}

Many advanced economies, including Japan and Singapore, face the specter of a shrinking labor force due to sustained decreases in fertility rates. The labor supply of many Asian countries is predicted to decrease over time, with the World Economic Forum projecting that Japan's workforce will be $20 \%$ smaller by 2040 compared to 2019 (Fleming 2019).

To maintain economic growth despite a shrinking labor force, there needs to be an increase in productivity resulting from upskilling of the workforce, improving business processes, and adopting technology. Another approach is to create opportunities for economically inactive segments of the population to enter or re-enter the workforce. These segments are very likely to require reskilling to confidently take on jobs in an environment where job tasks have been evolving rapidly due to technological disruptions.

In developing economies, the relatively large segment of unemployed youth represents an economic potential frequently referred to as a "youth dividend". The challenge is to ensure that the educational attainment of the young people match the needs of the growing economic sectors. An adaptive education and training system is required to ensure that the skill sets of those joining the labor force support the economic strategies of the country, including advanced technological skills (Fore 2018). 


\subsubsection{Extended Life Expectancy and Careers}

For the first time in history, humans are on average living more than 60 years, irrespective of the level of development in the countries in which they reside. According to the United Nations, this is one of the most significant social transformations of the twenty-first century (United Nations 2015). Life expectancy in Singapore stands at 83.6 years, one of the highest in the world (Department of Statistics 2019). The average Singaporean also enjoys the longest period of living in good health at 74.2 years (Ministry of Health 2018). Greater longevity and better health translate to longer working lives and delayed retirement (Vernon 2016). The proportion of Singaporeans aged 65 and older and still working increased from just $3 \%$ in 2010 to $7.2 \%$ of the workforce in 2019 (Hirschmann 2020). A similar trend is observed in the United States, with $31.9 \%$ of those aged 65 to 74 projected to still be working in 2022, up from 20.4\% in 2002 and 26.8\% in 2012 (Toosi 2013).

In a paradigm where people are living longer with active lives, the well-accepted three-stage approach to our typical lives-education, followed by work and then retirement-is becoming increasingly detached from reality. Gratton and Scott (2016) postulate that with greater longevity inching toward 100-year lifespans, this three-stage approach would have to evolve into a multistage iterative model of education-work-re-education-work, and so on (Gratton and Scott 2016). This is corroborated by Deloitte's projection that the half-life of skills will decrease to 5 years (Pelster et al. 2017), and that individuals embarking on a 30-year career would have to update and refresh their skills at least six times throughout their working life (Schwartz et al. 2017). This multistage, multiple-career life model entails substantial reskilling for individuals to move from one phase of their life to another, and to take on work that align with their experience and corresponding life-stage as they age.

\subsubsection{Coronavirus Disease Pandemic}

The trend of technology disruption impacting economies and societies that we have been witnessing since the start of the new millennium has been dramatically exacerbated by the outbreak of the COVID-19 pandemic in 2020, which resulted in massive disruptions to businesses across nearly every industry sector, impacting daily lives of entire populations across the globe.

The COVID-19 pandemic has accelerated the need for change in how businesses and individuals operate, in order to survive and adapt to public health and safety concerns. The power of technology is evident as companies and employees around the world switched to new working arrangements, enabled by digitalization of business processes, remote working, and online interactions and learning. Many companies have leveraged on technology to usher in new business models and to upskill employees during this period, and these models are likely to become the new norm postpandemic. 


\subsection{The Need for a New Learning Architecture for Powering Learning Societies}

The emerging digital age, combined with frequent disruptions and extended working lifespan, is engendering a situation where the ongoing employability of the workforce depends more heavily on the ability to acquire new skills in a timely manner throughout life, and less on initial qualifications earned during early education. To address this new reality, the education emphasis needs to shift from imparting subject knowledge to learners, to nurturing the propensity, efficacy, and self-agency to acquire new knowledge and skills. Avenues for learning have to be broadened to encompass multiple pathways and sources, given that many emerging skills are being defined and advanced by industry. Such emergent knowledge and skills often evolve at a rate faster than the ability of traditional education institutions to update their curriculum and equip their teachers.

Consequently, a new learning architecture (Fig. 14.2) is required for education and training systems to impart the necessary skills for new jobs and job tasks on an ongoing basis to accommodate the reskilling and upskilling needs of individuals. The learning architecture must be inclusive to cater to the needs of different population

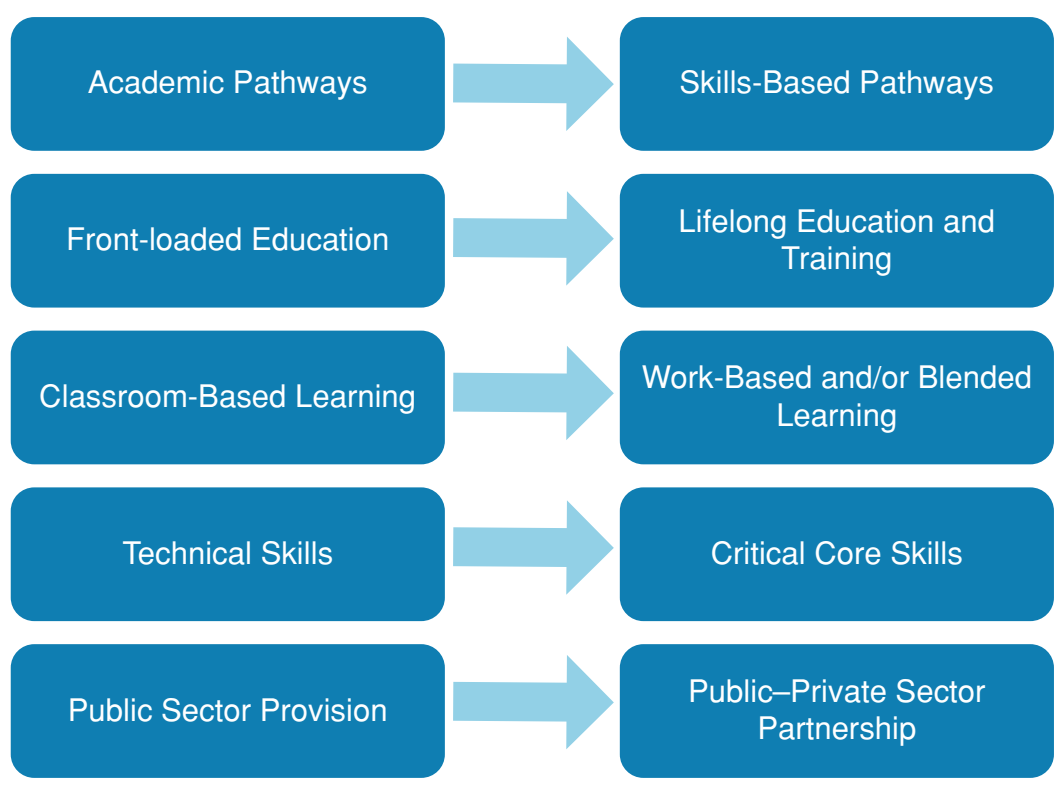

Fig. 14.2 Shifts in the new learning architecture (The emerging digital age is engendering a situation where the ongoing employability of the workforce depends more heavily on the ability to acquire new skills, and less on initial qualifications earned during early education). Source Authors' representation 
segments working in different industries, regardless of their age, financial status, or educational background.

\subsubsection{Academic Pathways to Skills-Based Pathways}

Academic education has been favored over vocational educational in many countries, as academic education is viewed as a more established route to career success and higher lifetime earnings (Korber and Oesch 2019). Globally, there has been a sharp increase in the proportion of individuals with tertiary education entering the workforce. In 1998, about $23 \%$ of those aged between 25 and 34 attained tertiary qualifications, and this proportion had nearly doubled to $42 \%$ by 2016 (OECD 2020). In Singapore, $48.2 \%$ of residents aged 25 and above attained tertiary qualifications in 2019 (Department of Statistics 2020).

Despite the increase in tertiary qualifications, the overall unemployment rate has steadily increased in many countries, particularly among the youth (Coskun 2019). Employers have also reported difficulties in filling certain job roles, suggesting a potential mismatch between demand and supply of workforce skills. Policy makers concerned with structural unemployment and underemployment are looking for ways to ensure that the stock of workforce skills meets the needs of the economy. To address these challenges, there is a need to shift from an academically oriented system to one that incorporates skills-based progression as mainstream pathways.

In Singapore, the Institute of Technical Education and Polytechnics offers a strong brand of education that is more vocational and skills-based in nature, to prepare students to enter the workforce upon graduation. The higher education landscape has been further diversified with the establishment of two applied universities - the Singapore Institute of Technology and the Singapore University of Social Sciences - in addition to the existing four academically oriented universities. The Ministry of Education announced in 2019 a target of $12 \%$ of every student cohort going through work-study pathways, with substantial emphasis on the acquisition of work-relevant skills at workplaces (Wong 2019). By developing work-study into a mainstream pathway and increasing the capacity of institutes of higher learning to deliver industry-relevant modular courses to support lifelong learning, more learners would be able to benefit from learning at workplaces and in the classrooms (Ang 2020). These multiple pathways are helping to bring about better matching of the aspirations of individuals with the specific needs of employers. 


\subsubsection{Front-Loaded Education to Lifelong Education and Training}

The reliance on an education paradigm that concentrates learning in the first 2 decades of individuals' lives cannot comprehensively inculcate in young adults the knowledge and skills required for the jobs of the future. The education system must shift toward equipping individuals with critical foundational skills in these early years, so that they can continually learn and remain adaptable throughout their lives as self-directed learners who take personal responsibility to develop and deepen their skills.

Learning institutions need to evolve beyond providing education and training based on fixed syllabi taught over specified durations, to delivery models that support learners in their lifelong quest for skills mastery. Learning institutions must evolve from their traditional focus on pre-employment learning to playing a larger role in continuing professional development. A fit-for-purpose continuing education and training sector is required to enable ongoing upskilling and reskilling of the workforce, in support of the changes and transformation of industries, governments, and societies. Individuals must be attuned to industry developments and needs, while employers must play their part to support and value continuous learning. In response to these needs, the institutes of higher learning in Singapore have established dedicated continuing education and training outfits to serve the wider workforce. Several universities have also set up mechanisms, such as alumni credits, to encourage their graduates to continue to upskill themselves throughout their careers.

\subsubsection{Classroom-Based Learning to Work-Based and Blended Learning}

Studies have shown that adult learning could be made more effective by offering different learning modes (Lawless 2019), and educational systems should move from classroom-based experiences to more holistic training approaches (Tan et al. 2018), incorporating blended modes such as work-based learning, remote learning, and workplace learning. Learning content has to be modular for learners to step in and out as needed, to efficiently acquire bite-sized knowledge and skills.

A holistic blended learning approach requires adjustment of educational delivery models, which are still predominantly classroom-centric and institution-centric in most countries. While there has been some experimentation in using technology tools for learning, such as video classes and immersive learning techniques, more has to be done in redesigning curricula and pedagogy to adapt to a paradigm where learning happens anywhere, anytime, and at any pace. A blended approach to incorporate multiple modes of learning is important, as knowledge and skills can be acquired through multiple channels, and certain skills are best acquired outside of classrooms, particularly in workplaces. 
Singapore has embraced this shift by working toward an institution-based system that strengthens work-based learning, through initiatives like enhanced internships and work-study programs, structured as cooperative education and contextualized for participant companies. In addition, the National Centre of Excellence for Workplace Learning was established in 2018 to help over 1000 companies, in particular small and medium-sized enterprises, to transform into learning workplaces, by building systems and best practices to train and develop their employees.

\subsubsection{Technical Skills to Critical Core Skills}

While employers have traditionally placed greater emphasis on technical skills, transversal or soft skills are becoming increasingly important, with employers favoring individuals who are able to think critically, communicate and collaborate effectively, and embrace change. This holistic focus on technical and soft skills presents an opportunity for employers to work closely with training institutions and government bodies to develop customized training programs for the workplace, and thus equip employees with the necessary technical and transversal skills to become more effective at work.

As part of the 4.5 billion Singapore dollar industry transformation program launched in 2016, which was overseen by Singapore's Future Economy Council, a set of 23 industry transformation maps were developed to raise productivity, skill sets, innovation, and internationalization of various industry sectors. In tandem, 34 skills frameworks have been developed to provide information on job roles, career pathways, and skills needed for employees to progress in each key sector of the industry. Co-created by employers, industry bodies, educational institutions, unions, and governmental agencies, these frameworks encapsulate descriptors of the occupational and/or technical and cross-cutting skills needed for each job role, including critical core skills into the domains of thinking critically, interacting with others, and staying relevant. This signals to individuals that working toward a promotion or a new job may not simply be about getting better technically at what they do, but also about picking up new skills such as collaboration and leadership. It also signals to employers that these areas must be addressed when developing their workforce, and to training providers to deliver on such skills needs.

\subsection{Public Sector Provision Versus Public-Private Sector Collaboration}

The public sector has traditionally played a principal role in the provision of educational opportunities by designing, developing, and funding education and training systems based on literacy goals and sensing of economic and societal needs. 
With the rapid and continual disruption of jobs and skills, significant involvement of the private sector is becoming increasingly vital to match the supply of skills from the education and training landscape with demand for skills needed for jobs across various industry sectors.

Both the public and private sectors should play important and complementary roles in the future of work (Bonic 2015). In particular, they should work in tandem to create a flexible and adaptive structure that provides relevant and accessible opportunities for lifelong learning. For instance, the public sector can redesign the curriculum of formal educational programs, and work with the private sector to infuse greater elements of work-based learning, through internships and cooperative arrangements, to impart work-relevant skills and critical core skills. Another possibility is for the private sector to curate leading-edge skills being championed by the industry (for example, artificial intelligence and robotics), and transmit such skills to the wider workforce. Such partnerships will facilitate strategic co-investments, align strategic directions, and spur joint initiatives between the two sectors.

Co-investing between the public and private sectors helps to reduce the public sector's fiscal burden in the provision of education and training opportunities, and reduces the burden on private enterprises in scouring for the right talents and skill sets required in today's fast-moving technology landscape. Such partnerships are win-win arrangements for both public and private sectors.

An example of a successful public-private partnership is the Salesforce Youth Programme, a joint collaboration between SkillsFuture Singapore and Salesforce. With subsidies for the initial training investment and first 6 months of salary, the program encourages employers to hire promising young employees without having to worry about their initial lack of relevant skills, providing youth with the opportunity to apply for jobs that they previously would not have been qualified for. This collaboration resulted in wins for the employee, employer, and government.

\subsubsection{Making Training Accessible and Affordable}

Ensuring the availability of skilled human resources is a high priority for all organizations irrespective of size. Apart from efforts by governments, employers will have to build up workplace learning capabilities to keep their workforce resilient, adaptable, and highly skilled. Employers face the challenge of ensuring that skill sets of employees meet the needs of their organizations as their business processes and requirements evolve. Some employers address the skills set challenge by hiring new staff, and inadvertently contributing to a growing problem where the demand for talent with specific skills outstrips the supply. Furthermore, the opportunity costs of ongoing training may be prohibitive for employees to undertake on their own accord.

Salesforce looked at this skills set challenge and saw an opportunity to democratize learning for an ever-evolving technological environment, not just for internal staff but also for the wider workforce. Thus, Trailhead (Fig. 14.3) was created to empower anyone to learn marketable skills for free. 
Salesforce

Trailhead

Skill up from anywhere for free

Learn In-Demand Skills

Learn new skills for the new normal the way you want, on-demand or from Trailhead Academy experts.

Earn Resume-Worthy Credentials

Prove your skills and skill-based badges and role-based credentials that lead to top jobs.

Connect to Opportunity

Connect to opportunities from mentorship to employment in the Trailblazer Community.

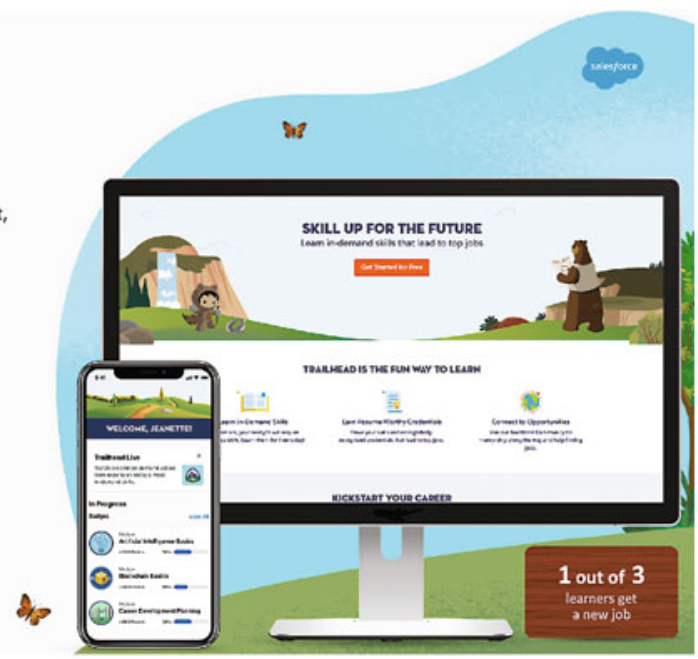

Fig. 14.3 Trailhead-Salesforce's learning experience platform (Trailhead is a learning platform created by Salesforce to allow members of the public to learn new technologies for free). Source Salesforce Inc. [2020]. Trailhead presentation. Unpublished. San Francisco

Similarly, UiPath, a global software company that has developed a platform that can emulate and automate actions of human activities, such as moving files and opening emails within a digital environment, offers a free and open online training platform called UiPath Academy available to people all over the world. UiPath Academic Alliance is a program that prepares students and experienced professionals for in-demand automation jobs upon graduation. UiPath has made its curriculum available to higher learning institutions and workforce development organizations across the world through the program.

Learning platforms like Trailhead and UiPath Academy are examples of how the private sector can upskill and reskill employees to combat the disruptions created by technological advancement. Offering training for free removes employers' reluctance to upskill their employees due to budgetary reasons, thereby making the quest for lifelong learning by employees more achievable.

\subsubsection{Positioning Lifelong Learning as a Public Good}

With lifelong learning becoming a necessity in a digital world where skills-in-demand continually evolve, the need for constant skills upgrading is becoming a "must have" in order to perform and retain one's job, and to live well in technology-enabled societies. However, the cost of training could be a major deterrence for organizations and individuals. The United Nations Educational, Scientific and Cultural Organization (UNESCO) report on Rethinking Education advocates that 
education should be viewed as a public good (Bokova 2015), and the rising need for lifelong learning raises the imperative to consider universal access and provision as a collective social endeavor. UNESCO further advocates the need for private businesses and civil society to invest in education beyond their immediate needs as this would help alleviate the strain on the state and bring about greater inclusivity.

In moving toward positioning lifelong learning as a public good, governments need to rethink their fiscal policies and governance principles relating to education and training. Ultimately, the goal is to make lifelong learning accessible and affordable to everyone. Governments should also involve the private sector and the community at large to be part of such an endeavor.

The SkillsFuture movement in Singapore is a case study of providing near universal access to education and training opportunities throughout life. With the provision of individual learning accounts (SkillsFuture Credit), subventions to lower the cost of training, and targeted programs for disadvantaged population segments, there is support for lifelong learning for people from all walks of life. Integration between formal and nonformal education and training systems help to establish multiple pathways for individuals to acquire relevant skills, regardless of their starting points. Multistakeholder partnerships with industry, trade bodies, and unions are part of the holistic and inclusive approach.

\subsection{Conclusions}

Technological advancements, demographic shifts, extended lifespans and careers, and the COVID-19 pandemic have led to major disruptions in the nature of work and workplaces. Businesses have to transform to compete and survive. To enable this transformation, businesses will need a skilled and adaptable workforce conversant with technology trends. Workers need to continually hone their capabilities to match the needs of businesses and remain employable throughout their working lives. These imperatives have further accentuated the need to speed up the development of learning societies, where access to lifelong learning for all supports the acquisition of relevant skills that will help businesses and individuals build resilience, increase their ability to adapt, and have the confidence to navigate an uncertain future.

The development of learning societies adaptive to the increasing pace of change calls for a new paradigm for education and training. The public sector has the opportunity to rethink existing education and training structures; to design a new learning ecosystem that is integrated, accessible, flexible, and agile-one that is highly responsive to the needs of industry and workforce. The private sector can play a key role in this ecosystem by early identification of new in-demand technologies and skills, creation of job opportunities for such skills, and contribution to accessible and affordable learning platforms and opportunities for the wider workforce. Companies should put in place favorable policies to support their employees in pursuing their lifelong learning pursuits. 
Drawing upon Singapore's experience, the following policy interventions could be considered by policy makers leading the development of learning societies within their respective countries:

(i) Establish a broad vision and plans to develop an integrated education and training system that provides multiple progression pathways for individuals to learn throughout life.

(ii) Implement mechanisms to make learning accessible to all, by developing the supply of relevant training delivered via multiple modes, and lowering the opportunity costs of learning.

(iii) Set directions and devise levers to expand the role of existing educational institutions to substantively support lifelong learning.

(iv) Undertake sustained actions to align and mobilize all key stakeholders, including government agencies, industry bodies, unions, and private companies to support inclusive outreach and effective functioning of the new learning architecture and systems.

These are the critical blocks to be overcome by an empowered learning society in order to build a more dynamic, holistic, and collaborative learning ecosystem; one that powers our economies and societies to confidently navigate current and future disruptions, and to emerge stronger in the new normal.

\section{References}

Ang, H.M. 2020. SkillsFuture work-study programmes to become "mainstream pathway" by 2025, benefit more students: Lawrence Wong. https://www.channelnewsasia.com/news/singapore/moeskillsfuture-work-study-programmes-lawrence-wong-13051458. Accessed 11 November 2020.

Bokova, I. 2015. Rethinking education: towards a global common good? Paris: UNESCO Publishing.

Bonic, I. 2015. 3 ways the private sector is filling skills and training gaps. https://www.weforum. org/agenda/2015/06/3-ways-the-private-sector-is-filling-skills-and-training-gaps/. Accessed 28 August 2020.

Bughin, J. et al. 2018. Skill shift: automation and the future of the workforce. McKinsey Global Institute. https://www.mckinsey.com/featured-insights/future-of-work/skill-shift-automa tion-and-the-future-of-the-workforce. Accessed 28 August 2020.

Coskun, S. 2019. Young, educated, unemployed. CRC TR 224 Discussion Paper Series. No. crctr224_2019_134. University of Bonn and University of Mannheim, Germany. https://ideas. repec.org/s/bon/boncrc.html. Accessed 1 September 2020.

Fleming, S. 2019. Japan's workforce will be $20 \%$ smaller by 2040. World Economic Forum. https://www.weforum.org/agenda/2019/02/japan-s-workforce-will-shrink-20-by-2040. Accessed 19 January 2020.

Fore, H. 2018. 7 ways for businesses to capture the youth dividend. https://www.weforum.org/age nda/2018/09/capturing-the-youth-dividend-7-ways-that-businesses-can-answer-the-calling-ofour-time/. Accessed 1 September 2020.

Government of Singapore, Department of Statistics. 2019. Complete life tables for Singapore resident population 2018-2019. Singapore: Statistics Singapore. https://www.singstat.gov.sg/-/ media/files/publications/population/lifetable18-19.pdf. 
Government of Singapore, Department of Statistics. 2020. Population trends 2020. Singapore: Statistics Singapore. https://www.singstat.gov.sg/-/media/files/publications/population/populatio n2020.pdf.

Government of Singapore, Ministry of Health. 2018. The burden of disease in Singapore, 1990-2017: an overview of the global burden of disease study 2017 results. Singapore: Epidemiology and Disease Control Division, Institute for Health Metrics and Evaluation.

Gratton, L., and A. Scott. 2016. 100-year life-living and working in an age of longevity, 1st ed. London: Bloomsbury Publishing.

Hirschmann, R. 2020. Employed residents aged 65 years and older as share of the employed resident population in Singapore from 1970 to 2019. https://www.statista.com/statistics/1112950/singap ore-elderly-share-of-employed-residents/.

Korber, M., and D. Oesch. 2019. Vocational versus general education: employment and earnings over the life course in Switzerland. Advances in Life Course Research 40: 1-13.

Kramer, L. 2019. What strategies do companies employ to increase market share? Investopedia. https://www.investopedia.com/ask/answers/031815/what-strategies-do-companies-employ-inc rease-market-share.asp. Accessed 1 September 2020.

Krishnan, K. 2020. Our education system is losing relevance. Here's how to unleash its potential. https://www.weforum.org/agenda/2020/04/our-education-system-is-losing-relevanceheres-how-to-update-it/. Accessed 1 September 2020.

Lawless, C. 2019. What is blended learning. https://www.learnupon.com/blog/what-is-blended-lea rning/. Accessed 28 August 2020.

Organisation for Economic Co-operation and Development (OECD). 2019. Education at a glance 2019: OECD indicators. Paris: OECD Publishing.

OECD. 2020. Population with tertiary education (indicator). https://doi.org/10.1787/0b8f90e9-en.

Pelster, B., Stempel, J., and van der Vyver, B. 2017. Careers and learning: real time, all the time. https://www2.deloitte.com/us/en/insights/focus/human-capital-trends/2017/learningin-the-digital-age.html.

Salesforce Inc. 2020. Trailhead Presentation. Unpublished. San Francisco.

Schwartz, J., Stockton, H., and Monahan, K. 2017. Forces of change: the future of work. https://www2.deloitte.com/us/en/insights/focus/technology-and-the-future-of-work/ overview.html. Accessed 1 September 2020.

Tan, J., et al. 2018. Business performance and skills survey. Singapore: Institute for Adult Learning. Toosi, M. 2013. Labor force projections to 2022: the labor force participation rate continues to fall. Monthly Labor Review. US Bureau of Labor Statistics.

United Nations. 2015. World population aging report. New York.

Vernon, S. 2016. Americans are living longer-and working longer. https://www.cbsnews.com/ news/americans-are-living-longer-and-working-longer. Accessed 1 September 2020.

Wong, L. 2019. MOE to ramp up workplace learning for students; work-study path for $12 \%$ of each student cohort by 2030. https://www.straitstimes.com/singapore/education/work-study-path-for12-of-each-student-cohort-by-2030. Accessed 1 November 2020 
The opinions expressed in this chapter are those of the author(s) and do not necessarily reflect the views of the Asian Development Bank, its Board of Directors, or the countries they represent.

Open Access This chapter is licensed under the terms of the Creative Commons Attribution-NonCommercial 3.0 IGO license (http://creativecommons.org/licenses/by-nc/3.0/igo/) which permits any noncommercial use, sharing, adaptation, distribution and reproduction in any medium or format, as long as you give appropriate credit to the Asian Development Bank, provide a link to the Creative Commons license and indicate if changes were made.

Any dispute related to the use of the works of the Asian Development Bank that cannot be settled amicably shall be submitted to arbitration pursuant to the UNCITRAL rules. The use of the Asian Development Bank's name for any purpose other than for attribution, and the use of the Asian Development Bank's logo, shall be subject to a separate written license agreement between the Asian Development Bank and the user and is not authorized as part of this CC-IGO license. Note that the link provided above includes additional terms and conditions of the license.

The images or other third party material in this chapter are included in the chapter's Creative Commons license, unless indicated otherwise in a credit line to the material. If material is not included in the chapter's Creative Commons license and your intended use is not permitted by statutory regulation or exceeds the permitted use, you will need to obtain permission directly from the copyright holder.

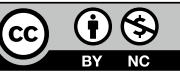

